\title{
Correction to: Life-threatening cardiac arrhythmias in congenital central hypoventilation syndrome
}

\author{
Eric Laifman ${ }^{1} \cdot$ Thomas G. Keens $^{1,2} \cdot$ Yaniv Bar-Cohen ${ }^{1,2} \cdot$ Iris A. Perez ${ }^{1,2}$ (D) \\ Published online: 11 February 2020 \\ (C) Springer-Verlag GmbH Germany, part of Springer Nature 2020
}

\section{Correction to: European Journal of Pediatrics} https://doi.org/10.1007/s00431-019-03568-5

The publisher regrets the original published version of this article, one of the author's name was incorrectly presented as "Yaniv Bar Cohen". The correct presentation should have been "Yaniv Bar-Cohen" and is now presented correctly in this article.

The original article has been corrected.

The online version of the original article can be found at https://doi.org/ 10.1007/s00431-019-03568-5

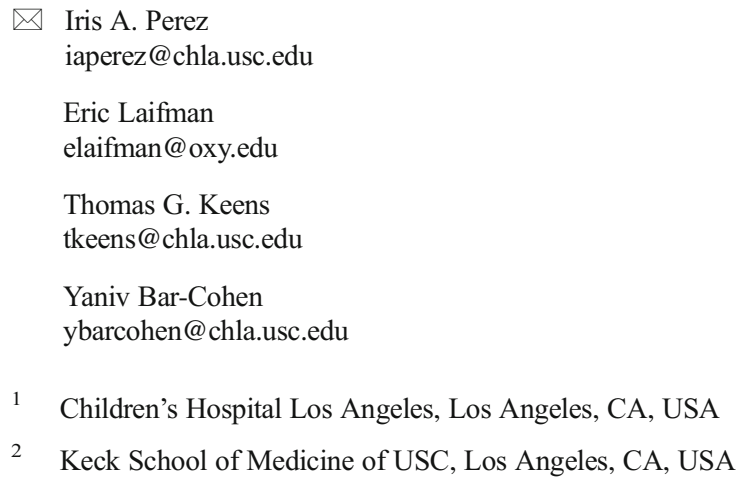

2 Keck School of Medicine of USC, Los Angeles, CA, USA 